\title{
IMPACT OF PARALLEL OPERATION OF AC TRACTION MOTORS ON LOCOMOTIVE PERFORMANCE
}

Presented paper deals with common problems of parallel operation of AC traction motors and presents some methods to investigate the basic impacts of the concept. A complex simulation model is introduced as well as results of simulations. Based on the results, a conclusion is made on locomotive performance impact.

Keywords: Traction drive, AC traction motor, parallel operation, tilting, adhesion.

\section{Introduction}

In many railway applications, $\mathrm{AC}$ induction traction motors are preferred as the best cost-effective solution for a modern locomotive. On the other hand, due to converter and $\mathrm{AC}$ motor prices, the investments are still higher than the DC traction drive application. Possible solution is to reduce number of traction converters and to use parallel connection of traction drives.

Unfortunately, parallel operation of AC induction machines introduces some problems with a vector control implementation and anti-wheel slip control. In addition, impact of bogies and locomotive frame tilting cannot be neglected. Finally, adhesion phenomenon should be considered, which leads to a very complex problem. Manufacturers and customers should consider investments vs. maintenance needs based on the impact of the solution. Based on the previous simulations in [1] and theory published e.g. in [2], locomotive performance is affected and thus should be expressed. Detailed analysis of parallel operation of AC traction motors is introduced below. Static simulation model is introduced, considering tilting forces, adhesion model and traction motors model, all in one complex simulation.

\section{Simulation model}

Energy analysis of a train movement helps us to focus on reasonable train operation types for hybrid drive applications. The key parameter is a kinetic energy, being developed with each acceleration and lost when braking [3] and [4].

\section{A. Tilting Model of a Locomotive}

Tilting phenomenon is well known and it is well described in [2] and [3]. Manufacturers introduced many systems how to lower the impact of tilting, e.g. levers, pneumatic cylinders, etc. The worst and the most generic wheel set involves no such systems. For 4-axle locomotive, the setup is shown in Fig. 1. Forces $\mathrm{F}_{1}$ to $\mathrm{F}_{4}$ are forces on wheels produced by traction drives, $F_{12}$ and $F_{34}$ are forces on pivots. Gravitation force $G$ is divided in two on pivots $G_{p 1}$ and $G_{p 2}$. The reaction forces on axles are $F_{n 1}$ to $\mathrm{F}_{\mathrm{n} 4} . \mathrm{F}_{\mathrm{t}}$ is traction force on a coupler.

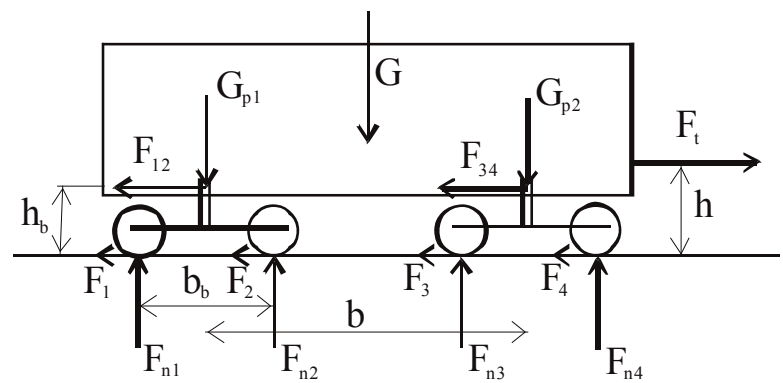

Fig. 1 Forces definition of a wheel set

Using static torque analysis, following equations (1) - (6) can be obtained.

$F_{n 1}=\frac{G_{p 1}}{2}-\left(F_{1}+F_{2}\right) \cdot \frac{h_{p}}{b_{p}}$

\footnotetext{
* 'Matej Pacha, ${ }^{2}$ Jiri Stepanek

${ }^{1}$ Faculty of Electrical Engineering, University of Zilina, Slovakia

${ }^{2} \mathrm{CZ}$ LOKO, a.s., Ceska Trebova, Czech Republic

E-mail: matej.pacha@fel.uniza.sk
} 
$F_{n 2}=\frac{G_{p 2}}{2}-\left(F_{1}+F_{2}\right) \cdot \frac{h_{p}}{b_{p}}$

$F_{n 3}=\frac{G_{p 2}}{2}-\left(F_{3}+F_{4}\right) \cdot \frac{h_{p}}{b_{p}}$

$F_{n 4}=\frac{G_{p 2}}{2}-\left(F_{3}+F_{4}\right) \cdot \frac{h_{p}}{b_{p}}$

$G_{p 1}=\frac{G}{2}-\left(F_{1}+F_{2}+F_{3}+F_{4}\right) \cdot \frac{h_{p}-h}{b}$

$G_{p 2}=\frac{G}{2}-\left(F_{1}+F_{2}+F_{3}+F_{4}\right) \cdot \frac{h_{p}-h}{b}$

The simulation model can be easily programmed in MATLAB Simulink, shown in Figs. 2 and 3.

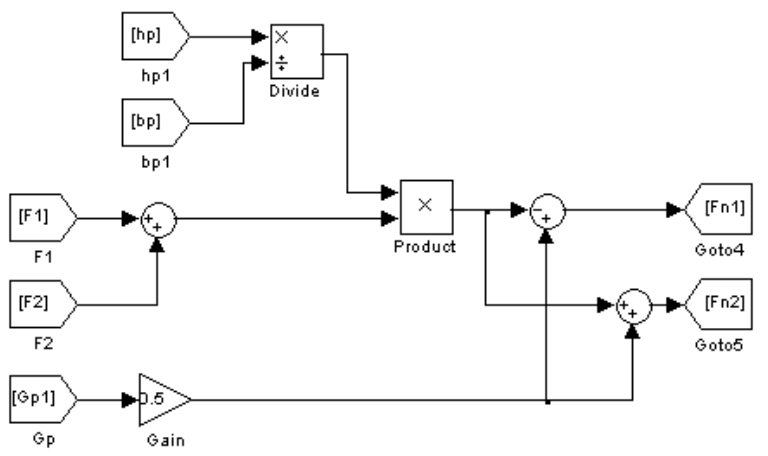

Fig. 2 Bogie (or two axle) tilting model in MATLAB Simulink (1) and (2) II.

\section{B. Model of Adhesion}

To simulate adhesion conditions of each axle, the slip model presented in [1] is introduced. In adhesive force transmission, some difference between a vehicle speed and a wheel speed is needed (a wheel creep [2]). There is a maximal adhesive force $\mathrm{F}_{\text {adh(max) }}$ that can be transmitted to the rail. Passing this maximum causes the more force is put on the wheel acceleration and the tractive force transmitted decreases (a wheel slip). The slip characteristics [2] and [5] can be described by (7) where $\mu$ is relative adhesive force in $\mathrm{N} / \mathrm{kN}, \mathrm{K}$ is a slope coefficient, $\varphi_{\mathrm{a}}$ is maximal relative adhesive force and $\Delta \mathrm{v}$ is actual wheel slip.

$\mu=\frac{2 K \varphi_{a}^{2} \Delta v}{\varphi_{a}^{2} \Delta \nu^{2}+K^{2}}$

Impact of adhesion conditions on the shape is given by $\varphi_{\text {a }}$ (8) [2], which is shown in Fig. 4,

$\varphi_{a}=c_{w} \cdot\left(\frac{7.5}{V+44}+0.161\right)$

where $\mathrm{c}_{\mathrm{w}}$ is a weather coefficient and $\mathrm{V}$ is a train speed in $\mathrm{km} / \mathrm{h}$. Low values of $c_{w}$ have similar impact as high speeds.

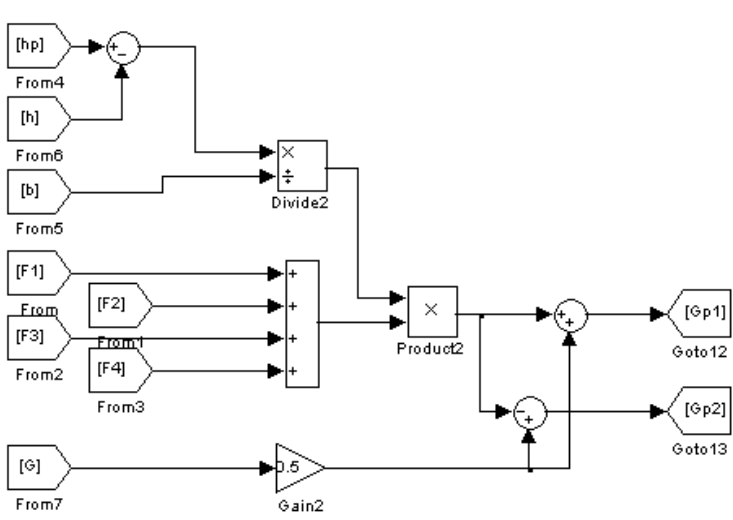

Fig. 3 Frame tilting model in MATLAB Simulink (5) and (6)

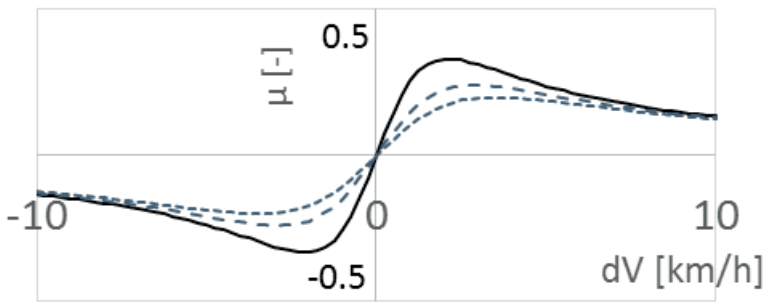

$-0 \mathrm{~km} / \mathrm{h} \quad----50 \mathrm{~km} / \mathrm{h}$

Fig. 4 Slip characteristics for different train speeds

Based on measurements in [4], there is a cleaning effect of the first axle of the locomotive. Assuming the first axle of the locomotive is the most lightened, the wheel creep is very intensive, thus power losses of the creeping wheels are higher. To conclude, the power losses cause the rail to be cleaner, thus, the second axle operates on better adhesion conditions. The situation can be transferred to the rest of the axles. Finally, a set of correction factors can be used to model this cleaning effect. For 4-axle locomotive, the cleaning effect coefficients are shown in Table 1. If an independent force control is applied, the overall adhesion utilization is actually higher than 1 [2] and [4]. In parallel operation/control of traction motors, the adhesion utilization is limited to the weakest axle in the wheel set.

The model is shown in Fig. 5. Adhesion limit is computed based on the train speed using (8) - block umax where g1 block is cleaning effect coefficient from Table 1. Finally, output axle force Fa1 is computed using (7) in block Slip. 


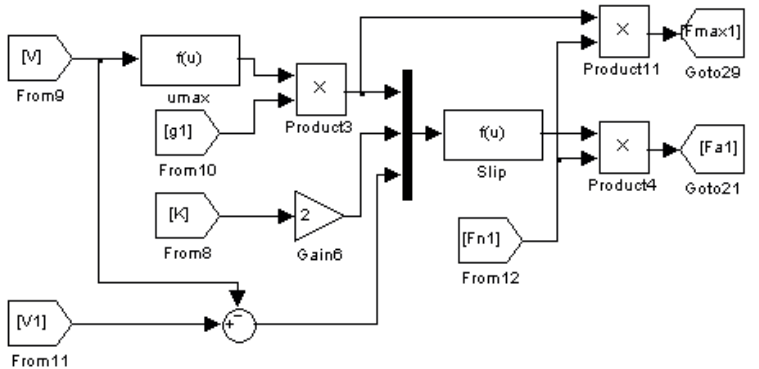

Fig. 5 Adhesion model in MATLAB - Simulink

CleaninG Effect Correction [1]

Table 1

\begin{tabular}{|l|l|l|}
\hline \multicolumn{1}{|c|}{ Axle } & \multicolumn{1}{c|}{ Correction } & \multicolumn{1}{c|}{ Error } \\
\hline 1 & 1 & - \\
\hline 2 & 1.232 & \pm 0.057 \\
\hline 3 & 1.313 & \pm 0.192 \\
\hline 4 & 1.512 & \pm 0.263 \\
\hline
\end{tabular}

\section{Model of Traction Motors}

Dealing with modern locomotives, AC induction motors (ATM) are the most common traction motors used. As far as the simulation is static, a dynamic model is not necessary. Static model of ATM is needed because of parallel operation of multiple motors where the output voltage and frequency is common for all the motors in the group. ATMs in parallel operation are usually controlled by a vector control algorithm, either single motor, or weighted multiple motor algorithm. Advantages of weighted control can be found in [6]. Nevertheless, in a quasi-static state, the output is still the voltage and the frequency. While one ATM can operate on its optimum, another can be overloaded or unloaded.

The model (Fig. 6) can be described by following equations (9) - (13). Parameters and variables used are:

$\begin{array}{ll}T_{e} \ldots \text { torque } & I_{R} \ldots \text { rotor current } \\ m \ldots \text { number of phases } & I_{S} \ldots \text { stator current } \\ \Omega_{S} \ldots \text { sync. angular speed } & U_{i} \ldots \text { back EMF voltage } \\ \text { S ... rotor slip } & U_{I f} \ldots \text { input voltage } \\ R_{R} \ldots \text { rotor resistance } & X_{\mu} \ldots \text { parallel reactance } \\ R_{S} \ldots \text { stator resistance } & Z_{A B} \ldots \text { subcircuit impedance } \\ X_{R} \ldots \text { rotor reactance } & j \ldots \text { complex component } \\ X_{S} \ldots \text { stator reactance } & \end{array}$

Using concrete ATM parameters, input voltage and frequency, electromechanical characteristics can be obtained. These characteristics are suitable for our simulation. While the ATMs are supplied by constant voltage and frequency, the train speed can be forced - decreased from synchronous speed (thus zero torque developed) to the speed of maximal tractive force, thus observing the wheel creep area. The wheel slip occurrence is a dynamic state which should be computed using dynamic simulation.

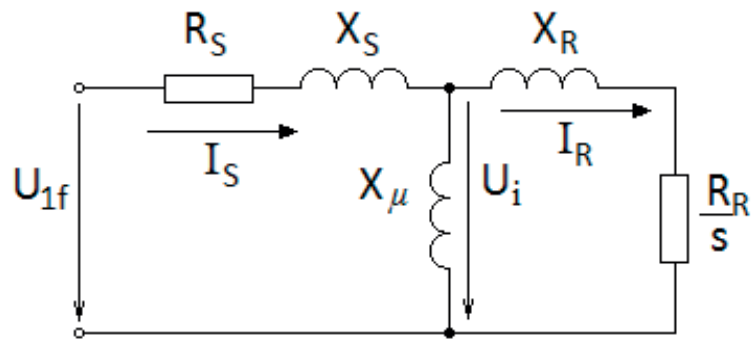

Fig. 6 AC Induction machine model scheme

$T_{e}=\frac{m}{\Omega_{s}} \cdot \frac{R_{R}^{\prime}}{S} \cdot I_{R}^{\prime 2}$

$I_{R}^{\prime}=\frac{\left|\vec{U}_{i}\right|}{\sqrt{\left(\frac{R_{R}^{\prime}}{S}\right)^{2}+X_{R}^{\prime 2}}}$

$\vec{U}_{i}=\vec{U}_{1 f}-\vec{I}_{S} \cdot\left(R_{S}+j \cdot X_{S}\right)$

$\vec{I}_{S}=\frac{\vec{U}_{1 f}}{\vec{Z}_{A B}+R_{S}+j \cdot X_{S}}$

$\vec{Z}_{A B}=\frac{1}{\frac{-j}{X \mu}+\frac{1}{\frac{R_{R}^{\prime}}{s}+j \cdot X_{R}^{\prime}}}$

Figure 7 shows the active part of electromechanical characteristics of ATM for diesel-electric locomotives of $450 \mathrm{~kW}$ rated power, operating at $200 \mathrm{rpm}$ of synchronous speed. Motor parameters are marked as confidential. The characteristics are recalculated considering a gearbox ratio and a wheel diameter respectively.

\section{Overall Simulation Model}

Following the Introduction, the main purpose of this model is to make a complex simulation of a traction drive considering tilting forces, adhesion conditions and motor characteristics, to investigate impacts of parallel ATM operation on wheel's wear and traction characteristics, including adhesion.

Traction drive is modelled as steady state set of four ATMs in parallel operation (all motors supplied by the same voltage and frequency), but with different load and speed. Tilting forces are computed based on a static model of the wheel set of Bo'Bo' (4-axles in 2 bogies setup) locomotive. Adhesion model is made of four independent slip characteristics, one for each axle. There 
is an algebraic loop preventing integrator using a small time constant to avoid an impact on the computation (Fig. 8).

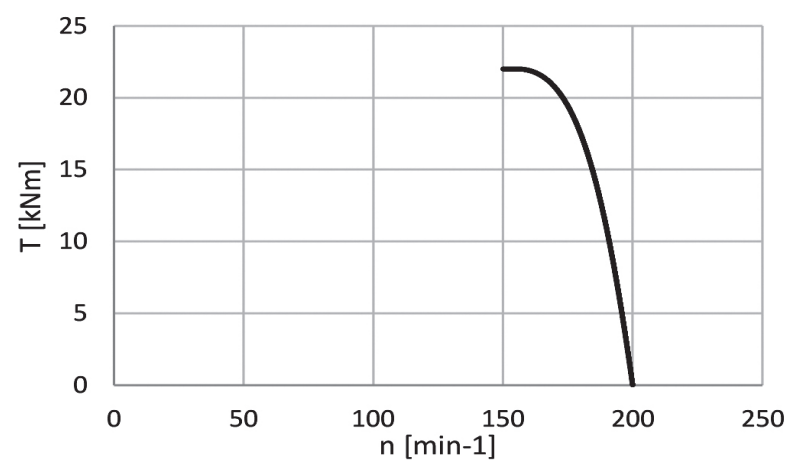

Fig. 7 Electromechanical characteristics of ATM (450 kW) @200 RPM of synchronous speed

The whole simulation is driven by a vehicle speed instead of time, thus no dynamic effects are simulated. Since two main effects - axle wear and traction characteristics impacts - are investigated, additional calculations are made. The first one is a power drop on the wheel-to-rail contact, pointing at the level of wheel wear (wheel slip percentage can be used as well) [7] and [8]. The more power the more wheel wear. The second one is locomotive adhesion utilization coefficient (14),

$\varepsilon=\frac{M I N\left(F_{\text {max }}\right)}{\varphi_{a} \cdot n \cdot G}$

where $\mathrm{MIN}\left(\mathrm{F}_{\text {imax }}\right)$ is a minimum of maximal tractive forces on wheels, $n$ is number of axles and $G$ is gravity force of the locomotive. The model can be also extended or used in timedomain simulation with dynamic analysis as in [9].

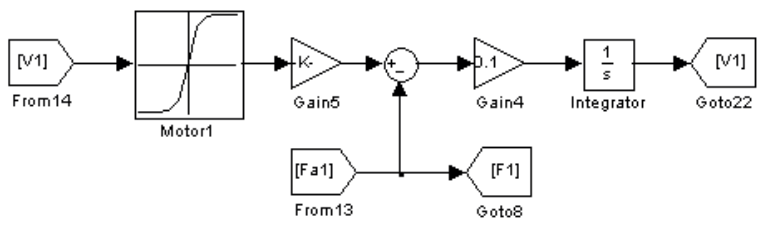

Fig. 8 Connection between ATM characteristics, traction force and axle speed

\section{Simulation results}

Simulation introduces 4-axle wheel-set configuration with considering the cleaning effect of the creeping wheels. All 4 traction motors are driven from single traction converter. Wheel set dimensions used in the simulations correspond to a common 4-axle diesel-electric locomotive (where $\mathrm{h}<\mathrm{h}_{\mathrm{b}}$ ). Conclusion is made based on relative results.
As described in Table 1, the cleaning effect grows from the first to the last axle of the wheel set in direction of movement. Following charts show the simulation considering the coefficients from Table 1

In Fig. 9, Axles No. 2 and No. 4 are in charge while axles No. 1 and No. 3 are lightened. The smaller difference between axles 2 and 4 is caused by the cleaning effect and resulting axle forces.

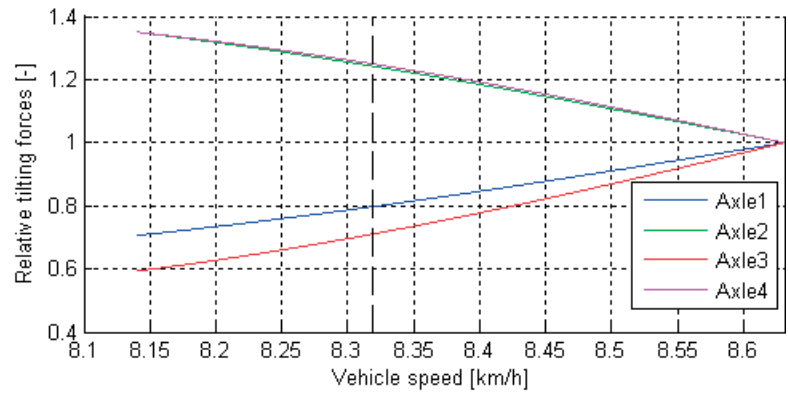

Fig. 9 Relative tilting forces including cleaning effect, using $h r_{h} b$

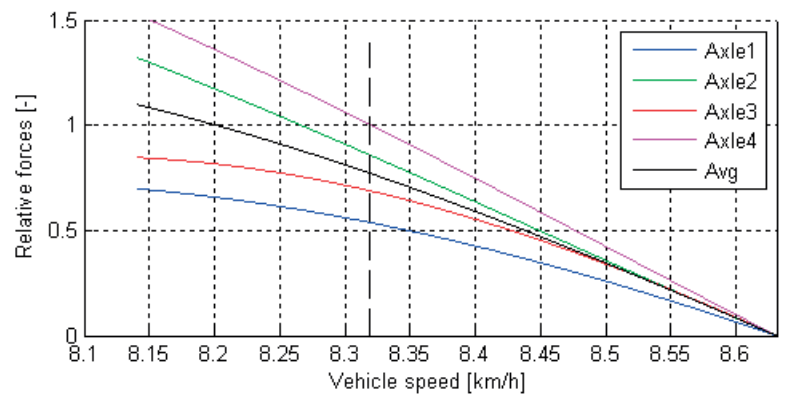

Fig. 10 Relative axle forces $(1=$ nominal value $)$, excluding cleaning effect, using $h<h b$

Figure 10 shows the most loaded ATM is on $4^{\text {th }}$ axle. Obviously, the reason is the cleaning effect of the first axles creeping. The overall tractive force is at $77.06 \%$ of nominal if none of the ATMs is overloaded. This means, the locomotive performance is lower than expected. In case of the currents are not measured separately for each ATM, overloading of ATMs can be caused by setting the locomotive output to the "rated" force (theoretically computed).

\section{Conclusion}

The article introduces a complex static simulation model of 4-axle locomotive traction drive in speed domain. The model connects several aspects of $\mathrm{AC}$ traction drive simulation in parallel operation.

The simulation model is based on static tilting model of 4-axle diesel-electric locomotive, which can be used for electric locomotives as well. Nevertheless, the AC traction drive with 
parallel operation is much more typical solution for dieselelectric concepts. The model considers individual axle forces and introduces independent adhesion models, including the cleaning effect of creeping wheels.

AC traction drive is modelled as a static characteristic of induction traction motor, which fits the static simulation needs.

Tilting forces create different adhesion conditions for each axle. The first axle in the movement direction is always lightened, while second, etc. is more loaded. If an individual traction drive control is used, overall traction force can be even higher than with a common traction drive [4]. In a parallel traction drive operation, natural electro-mechanical characteristics of the drive should be taken into account. In case of induction traction motors operating at common (constant) voltage and frequency, one of the motors operates at higher load (usually up to nominal) while the other motors operate at lower load. The overall tractive force is then lower, about $77 \%$ of the ideal value. This is even lower than the theoretical value of the DC traction drive $83 \%$ [4].

The main concern is connected with different performance of the motors commonly driven. If none of the motors is overloaded, the last motor (in the movement direction) operates on its rated current and the other motors' load is reduced due to higher wheel creep. Locomotive performance data should be reduced if traction motors operate in parallel. To keep the locomotive performance higher, the traction drive configuration should involve at least two groups of parallel driven traction motors with independent wheel creep control [10].

\section{Acknowledgment}

Authors would like to thank CZ LOKO Company for input data and consultations. The article has been supported by project VEGA $1 / 0794 / 14$.

\section{References}

[1] PACHA, M., STEPANEK, J.: Modelling of Parallel Operation of AC Traction Motors Considering Adhesion and Tilting. Proc. of Intern. Conference Elektro, 2014 , pp. 352-357, May 2014

[2] DANZER, J.: Electric Traction / Elektricka trakce (in Czech), ZCU Plzen, vol. 7, November 2008.

[3] IWNICKI, S.: Handbook of Railway Vehicle Dynamics CRC Press, Taylor \& Francis Group, Boca Raton, 2006.

[4] DANZER, J.: Wheelslip on bogie with AC Traction Motors / Skluz podvozku s asynchronnimi trakcnimi motory (in Czech), Elektrotechnicky obzor 80, 1991, pp. 1-12.

[5] POLACH, O.: Contact of Wheel and Rail in Computer Simulation of Vehicle Dynamics and Axle Drive Dynamics, Communications - Scientific Letters of the University of Zilina, vol. 1, 2001, pp. 11-17, ISSN 1335-4205.

[6] SKUDENLY, H.-CH., WEINHARDT, M.: An Investigation of the Dynamic Response of Two Induction Motors in a Locomotive Truck Fed by a Common Inverter, Industry Applications, IEEE Transactions, vol. IA-20, No.1, pp.173-179, Jan. 1984.

[7] BOSSO, N., ZAMPIERI, N.: Experimental and Numerical Simulation of Wheel-Rail Adhesion and Wear Using a Scaled Roller Rig and a Real-Time Contact Code, Hindawi Publishing Corporation [online], 2014, Article ID 385018, p. 14.

[8] KUMAR, S., ALZOUBI, M. F., ALLSAYYED, N. A.: Wheel/rail Adhesion Wear Investigation Using a Quarter Scale Laboratory Testing Facility, Railroad Conference, 1996, Proc. of the 1996 ASME/IEEE Joint, pp. 247-254, Apr-May 1996.

[9] ONDROVA, Z.: Dynamic Analysis of a 4-axles Railway Vehicle Model, Communications - Scientific Letters of the University of Zilina, vol. 2, 2009, pp. 65-69, ISSN 1335-4205.

[10] YAMASHITA, M., SOEDA, T.: A Novel Slip Control Method Considering Axle-weight Transfer for Electric Locomotive, Vehicle Power and Propulsion Conference (VPPC), 2010 IEEE , pp.1,6, 1-3 Sept. 2010. 